\title{
Reproductive Biology of the Assam Forest Frog, Hydrophylax leptoglossa (Cope 1868) (Anura: Ranidae), from Lawachara National Park, Bangladesh
}

\author{
Md. Mokhlesur Rahman, Md. Fazle Rabbe, and Md. Mahabub Alam
}

Department of Zoology, University of Dhaka, Dhaka 1000, Bangladesh (mmrahman48@du.ac.bd)

$\mathrm{B}$ angladesh is home to 49 amphibian species residing in mixed evergreen, deciduous, and mangrove forests as well as other densely vegetated habitats (IUCN Bangladesh 2015). However, little information is available on the breeding biology of most species; exceptions are the Common Asian Toad, Duttaphrynus melanostictus (Ahmed and Alam 2015), the Indian Bullfrog, Hoplobatrachus tigerinus (Joly 1992), and the Red Narrow-mouthed Frog, Microhyla rubra (Ahmed and Alam 2015). Herein, we provide some observations on the reproductive biology of the Assam Forest Frog, Hydrophylax leptoglossa (Cope 1868), in Bangladesh.

Hydrophylax leptoglossa is a medium-sized (SVL 45-70 $\mathrm{mm})$, nocturnally active, terrestrial insectivore, typically

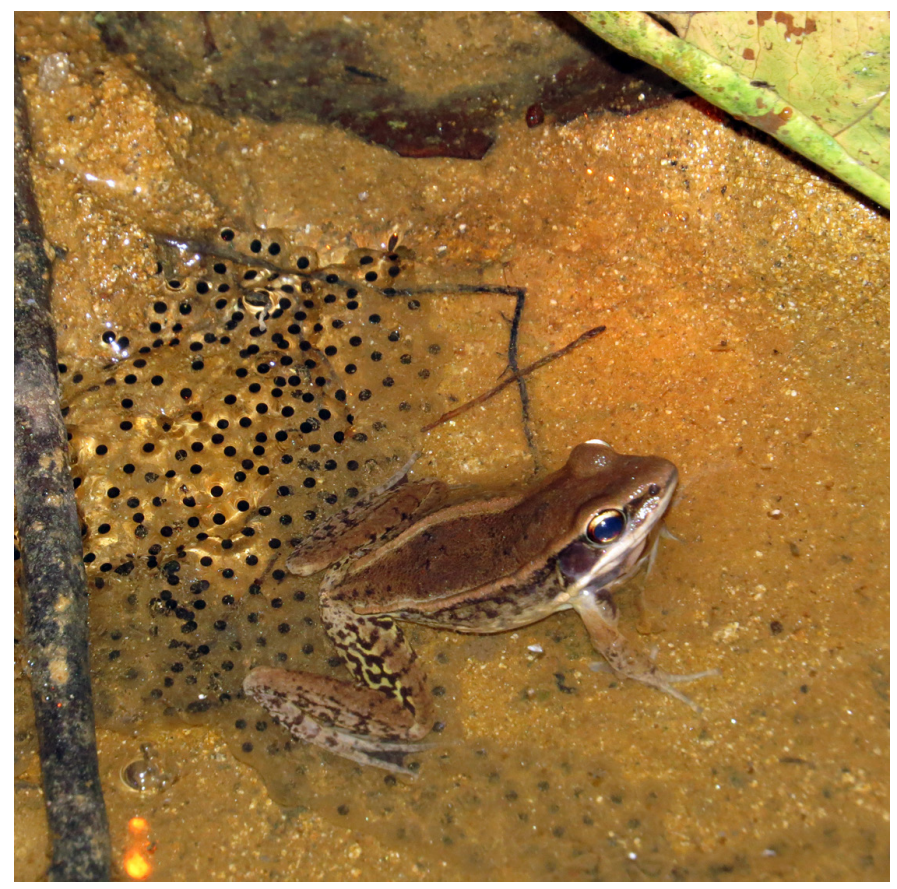

Fig. 1. An adult female Assam Forest Frog (Hydrophylax leptoglossa) depositing its eggs in a pool in the Lawachara National Park. Photograph by Md. Mokhlesur Rahman. found on the forest floor, under fallen logs, and bushes close to water; it breeds in canals, streams, and stagnant water with vegetation (Chakma 2009). The species is distributed in eastern India (Assam, Mizoram, Tripura, Meghalaya), Bangladesh, southern Myanmar, and western Thailand (Ahmed 2015; Frost 2017; IUCN SSC Amphibian Specialist Group 2016). In Bangladesh, the species is encountered most frequently in mixed evergreen forests, deciduous forests, and other densely vegetated areas (Ahmed 2015).

At approximately $2100 \mathrm{~h}$ on 14 April 2017, we observed an adult female (SVL $53.0 \mathrm{~mm}$, mass $9.8 \mathrm{~g}$ ) laying its eggs (Fig. 1) in a small sand-bottomed pool ( $40 \times 25 \times 5-8 \mathrm{~cm}$; Fig. 2) approximately $1.5 \mathrm{~m}$ from a stream with clear stag-

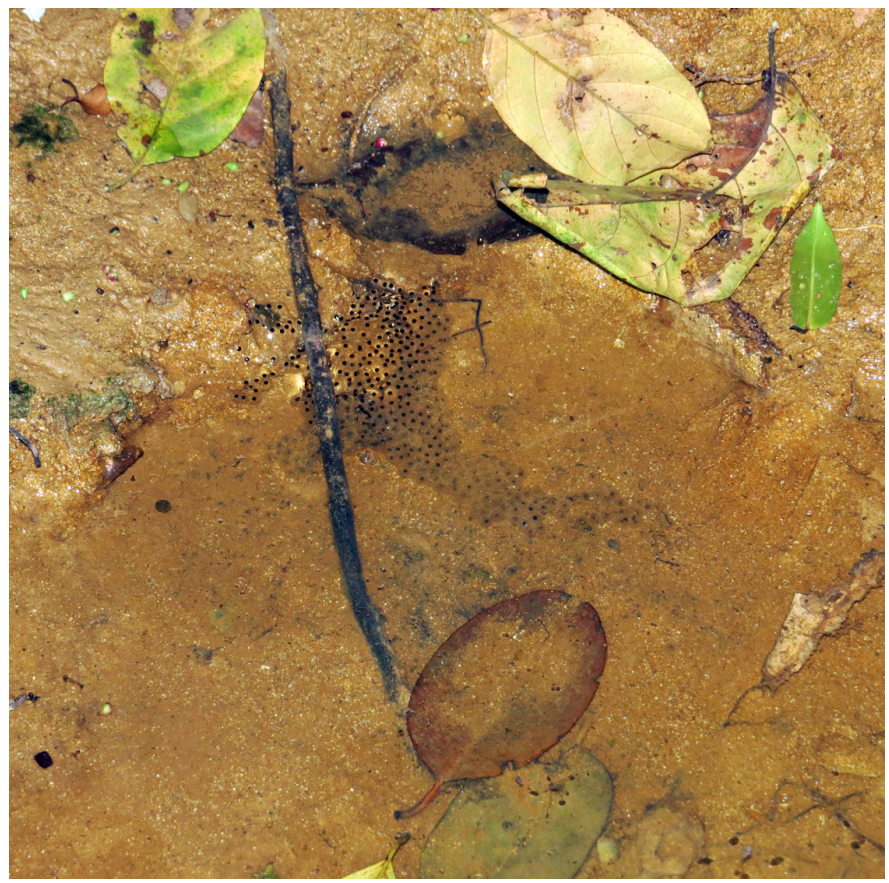

Fig. 2. The egg clutch of an Assam Forest Frog (Hydrophylax leptoglossa) in a small sand-bottomed pool in the Lawachara National Park, Bangladesh. Photograph by Md. Mokhlesur Rahman. 


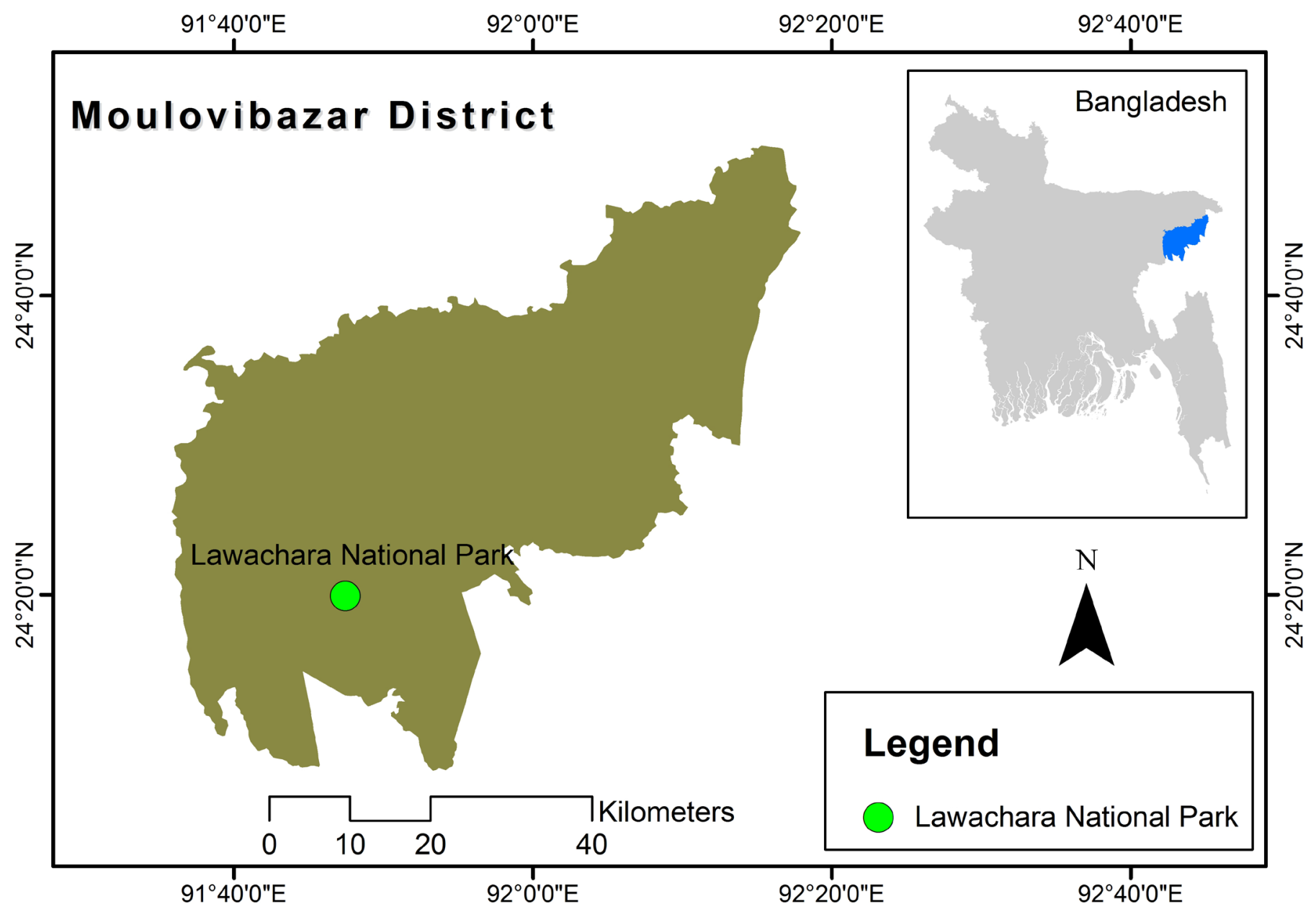

Fig. 3. Map showing the location of Lawachara National Park, where we observed egg deposition by an Assam Forest Frog (Hydrophylax leptoglossa).

nant water and a sandy-clay bottom filled with dead leaves and twigs in the Lawachara National Park $\left(24^{\circ} 19^{\prime} 55^{\prime \prime} \mathrm{N}\right.$, $091^{\circ} 47^{\prime} 40^{\prime \prime E}$ ), Bangladesh (Fig. 3). An adult male (SVL 44.8 $\mathrm{mm}$, mass $5.6 \mathrm{~g}$ ) was in close proximity to the female (Fig. 4). The nearest vegetation was $3-4 \mathrm{~m}$ away and the pool was exposed to direct sunlight. Temperature and relative humidity at the site were $28^{\circ} \mathrm{C}$ and $67 \%$, respectively. Several additional male Assam Forest Frogs and males of other species (Smith's Litter Frog, Leptobrachium smithi; Dark-sided Frog, Sylvirana nigrovittata) were calling in the immediate vicinity.

We did not have permission to collect the species, which is protected under Schedule II of the Bangladesh Wildlife (Conservation and Security) Act, 2012. However, after egg deposition was complete, we captured and measured both frogs before releasing them in the pool. We counted 253 eggs; egg diameters were $0.9-1.2 \mathrm{~mm}$ (mean $=1.03 \pm 0.11 \mathrm{~mm}$, $\mathrm{n}=10$ ). After three days, almost all of the eggs had hatched into dark brown to black tadpoles that measured 2.9-3.2 $\mathrm{mm}$ in total length (mean $=3.04 \pm 0.1 \mathrm{~mm}, \mathrm{n}=10)$. Seven days later, we counted only 110 tadpoles $(43.5 \%)$, with total lengths of 4.8-5.9 mm (mean $=5.4 \pm 0.4 \mathrm{~mm}, \mathrm{n}=10)$. The low number of tadpoles might have been attributable to a

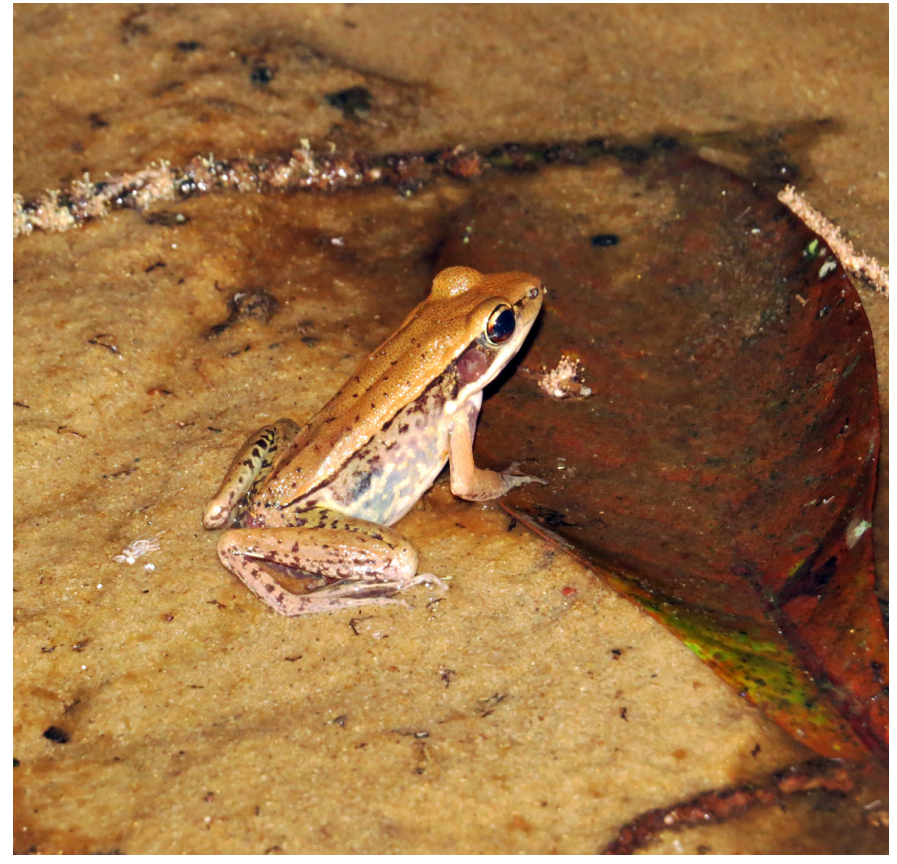

Fig. 4. An adult male Assam Forest Frog (Hydrophylax leptoglossa) was in close proximity to the female depositing its eggs. Photograph by Md. Mokhlesur Rahman. 
number of unfertilized eggs, predation, or unintentional damage inflicted by humans moving through the pool.

\section{Acknowledgements}

We express our gratitude to Mr. Mihir Kumar, Divisional Forest Officer, for permitting us to work in the Lawachara National Park. We thank Mr. M.A. Hossain, official of the Forest Department, for accompanying us in the field. We also thank Mr. M. Salauddin for assistance with preparation of the map. This study was partially supported by the University Grants Commission, Bangladesh (Grant no: Reg/Admin-3/65676-78).

\section{Literature Cited}

Ahmed, A. 2015. Hylarana leptoglossa, p. 259. In: IUCN Bangladesh. Red List of Bangladesh, Volume 4: Reptiles and Amphibians. IUCN Bangladesh Country
Office, Dhaka, Bangladesh.

Ahmed, F. and S.M.I. Alam. 2015. An observation of winter breeding by two anurans from Bangladesh. Reptiles \& Amphibians 22: 29-31.

Chakma, S. 2009. Sylvirana leptoglossa, pp. 34-35. In: S.M.H. Kabir, M. Ahmad, A.T.A. Ahmed, A.K.A. Rahman, Z.U. Ahmed, Z.N.T. Begum, M.A. Hassan, and M. Khondker (eds.), Encyclopedia of Flora and Fauna of Bangladesh. Volume 25: Amphibians and Reptiles. Asiatic Society of Bangladesh, Dhaka, Bangladesh.

Frost, D.R. 2017. Amphibian Species of the World: An Online Reference. Version 6.0 (21 January 2018). American Museum of Natural History, New York, USA (http://research.amnh.org/herpetology/amphibia/index.html).

IUCN Bangladesh. 2015. Red List of Bangladesh, Volume 4, Reptiles and Amphibians. IUCN Bangladesh Country Office, Dhaka, Bangladesh.

IUCN SSC Amphibian Specialist Group. 2016. Hydrophylax leptoglossa. The IUCN Red List of Threatened Species 2016: e.T58642A64131614 (http://dx.doi. org/10.2305/IUCN.UK.2016-3.RLTS.T58642A64131614.en).

Joly, R.A. 1992. Studies on some aspects of breeding biology of Bull Frog (Rana tigrina). Unpublished M.Sc. Thesis, Department of Zoology, University of Dhaka, Bangladesh. 